\title{
Road Accidents Prevention and Detection
}

\author{
Kesi Reddy Sandeep \\ AV hostel- 345, ECE-III year Sastra \\ University, Tanjore \\ Tamilnadu-613402, India
}

\author{
Ailneni Sahith \\ AV hostel- 345, ECE-III year Sastra \\ University, Tanjore \\ Tamilnadu-613402, India
}

\author{
M.Rohit Reddy \\ AV hostel- 345, ECE-III year Sastra \\ University, Tanjore \\ Tamilnadu-613402, India
}

\author{
P. Avinash Babu \\ AV hostel- 345, ECE-III year Sastra \\ University, Tanjore \\ Tamilnadu-613402, India
}

\author{
K. Surya Teja \\ AV hostel- 345, ECE-III year \\ Sastra \\ University, Tanjore \\ Tamilnadu-613402, India
}

\begin{abstract}
"To realize the value of one second, ask the person who has survived an accident."

Transportation plays a key role in development of a country. Travel, mainly road travel is inevitable to any individual. With at least 13 people dying every hour on Indian roads, India had topped the global list of deaths in road accidents (global status report, WHO).

Roads are the key access to many places. Places situated over the mountain ranges are sometimes accessible only by roads. Thus ghat roads play a important role in the road transport system. In Ghat roads, the major accident prone zones are U- turns where the approach of vehicles in opposite direction is almost invisible which results in fatal accidents. Besides prevention, the acknowledgement of accidents is a major problem due to poor communication facilities.

India doesn't have a scientific traffic engineering which forms the basis of road safety improvement. Though many conventional methods were implemented, they proved largely unsuccessful. We propose a scientific approach to this problem. Our proposal to prevent this phenomenon is to detect the vehicles approaching the turn by using sensors and to warn the vehicles in opposite direction. To detect the occurred accidents in time, we use electronic toll systems.
\end{abstract}

The full text of the article is not available in the cache. Kindly refer the IJCA digital library at www.ijcaonline.org for the complete article. In case, you face problems while downloading the full-text, please send a mail to editor at editor@ijcaonline.org 